\title{
FINITE ELEMENT ANALYSIS OF SHADED POLE MOTOR BASED ON MAXWELL2D
}

\author{
*Adnan J. Kazem ${ }^{1}$
}

Amer M. Ali ${ }^{1}$

1) Electrical Engineering Department, College of Engineering, Mustansiriyah University, Baghdad, Iraq

\begin{abstract}
Shaded pole induction motor is one of the simplest and least expensive types of single-phase motors, but one of the most difficult to analyze. In this paper, we adopted a two-dimensional finite element method 2DFEM, which is one of the most accurate methods to analyze such motors. We used Ansys Maxwell2D software with assist of AutoCAD software in modeling and analyzing a reluctance-augmented shaded pole motor. The 2DFEM results of torques and currents for this motor obtained from Maxwell2D were compared with the analytical results and appeared a good agreement.
\end{abstract}

Keywords: shaded pole induction motor, finite element analysis, Ansys Maxwell2D.

\section{Introduction}

The great development in computers has led to the spread of analysis using the finite element method (FEM), as this method is considered one of the best methods in the analysis of electric motors, especially the shaded pole induction motor (SPIM), as it is considered one of the most difficult motors in terms of analysis and study. The reason for the complication is the increase in space harmonics and the existence of different sets of leakage inductances in the stator [1]. By FEM we can able to go inside the motor and perform a deep analysis of the magnetic field distribution [2]. The use of FEM in calculating the various electromagnetic quantities, such as the magnetic flux density in the static state (zero frequency) and at a frequency of $50 \mathrm{~Hz}$. This allows us to discover areas of high saturation. The rotor skewing angle was also implemented and the electromagnetic torque was calculated [3]. There are two types of analysis, 2D and 3D for electrical machines, where it was found that although 3D analysis consumes more time in computing and storage, the improvement in performance achieved using 3D analysis is not very significant because the difference was very small [4]. The study and analysis of the transient finite elements in three-dimensional or twodimensional dimensions aim to achieve the lowest cost and highest efficiency. Minimum raw materials and costs can also be achieved through the introduction of the new stator structure. Finite element analysis can be used on a large scale and utilized [5]. There is a research gap in the field of declaring all the details of modeling a shaded pole motor especially in the shading ring simulation. This research gap prompted us to propose a clear method showing the details of modeling and analyzing this motor based on both Maxwell and AutoCAD software.

*Corresponding Author: adnan.j.eng@gmail.com 


\section{Finite Elements Method (FEM)}

The FEM has become the main tool for calculating magnetic fields in electrical machines, as the engineer can solve problems that are difficult to solve through analytical methods, such as the effect of harmonics, complex magnetic field and saturation in different parts of the motor. As this method enables us to enter inside the motor and conduct a deep analysis of it $[1,3]$.

All field models for finite element analysis of different types of induction motors are based on Maxwell's equations.

$$
\nabla \cdot D=\rho \quad \text { Gauss' law }
$$

$\nabla \cdot B=0 \quad$ Gauss' law for magnetism

$\nabla \times E=-\frac{\partial B}{\partial t} \quad$ Faraday's law

$\nabla \times H=\frac{\partial D}{\partial t}+J \quad$ Ampere-Maxwell law

Where:

$(D)$ is the electric displacement field, in $\left(C \cdot \mathrm{m}^{-1}\right)$

$(\rho)$ is the resistivity of the material in $(\Omega . \mathrm{m})$

$(B)$ is the vector term of magnetic flux density expressed in (tesla)

$(E)$ is the electric field in $\left(\mathrm{V} . \mathrm{m}^{-1}\right)$

$(H)$ is the magnetic field in $\left(\mathrm{A} . \mathrm{m}^{-1}\right)$

$(J)$ is the current density in (A. $\left.\mathrm{m}^{-2}\right)$

\section{Ansys Maxwell Software}

Maxwell is a powerful finite element analysis software designed to simulate different types of electrical machines. Maxwell solves the problems of the electromagnetic field by solving Maxwell's equations in a region of finite elements with suitable boundary conditions. In order to solve the set of algebraic equations, the geometry of the problem in the model is automatically divided into elements. All surfaces of the motor 2D model are divided automatically to finite elements by mesh. In order to obtain a better solution accuracy, the meshing density must be increased. The finite element analysis software used in this work is Ansys Maxwell 16, The RMxprt tool is a subprogram integrated with Ansys Maxwell and it is contain a ready-made templates but the shaded pole motor is not included in these templates, so we used AutoCAD program in drawing the stator and then transferred it to Maxwell, while the rotor is modeled by Maxwell ready-made templates. In this paper we used 2DFEM analysis because 3DFEM analysis requires increased solution time. The degree of the results accuracy improvement with 3DFEM analysis is not relatively rewarding and therefore 2DFEM analysis is sufficient for analyzing small electric motors like shaded-pole one [4].

\section{Shaded Pole Motor Modeling by Ansys Maxwell}

Table (1) and Figures (1) \& (2) show the design data of test shaded pole motor type reluctance augmented.

Table 1. Shaded Pole Motor Data

\begin{tabular}{lc}
\hline Supply Voltage & $220[\mathrm{~V}]$ \\
Frequency & $50[\mathrm{~Hz}]$ \\
Rated power & $65[\mathrm{~W}]$ \\
Rated speed & $2900[\mathrm{rpm}]$ \\
Number of poles & 2 \\
Turns/coil & 900 \\
Wire diameter & $0.28[\mathrm{~mm}]$ \\
Number of slots in stator & 2 \\
Shaded pole ring & $(1.2 \times 6.5)[\mathrm{mm}]$ \\
Number of slots in rotor & 17 \\
Rotor bars skew angle & $22.5^{\circ}$ \\
\hline
\end{tabular}




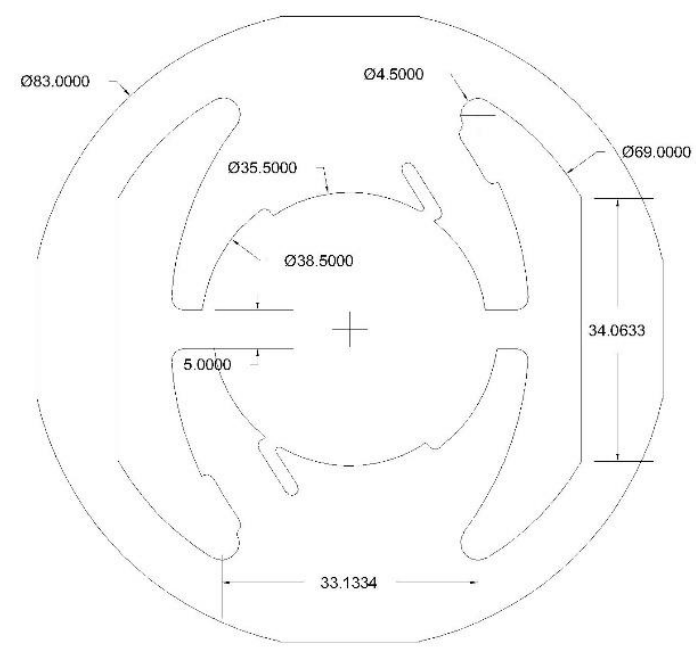

Figure 1. Stator lamination of SPIM

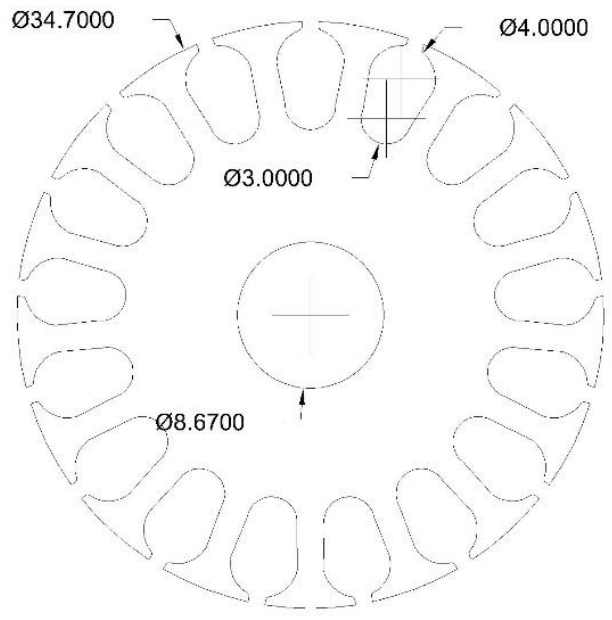

Figure 2. Rotor lamination of SPIM

The above mentioned test rotor dimensions were entered through the interactive windows of the RMxprt sub-program, and we imported the stator pre-designed drawing from AutoCAD to Maxwell. After that we defined the materials properties for each part of the motor model, the copper for the main winding and the shading ring for stator, and the silicon steel according to its B-H curve for the stator and rotor laminations, and pure aluminum for rotor bars and slip rings. A special task was performed to define the shading ring as an end connection and give it its own parameters. Then we defined the main winding data like winding resistance and inductance. After that we assigned a band of motion in Maxwell 2D. Two or more motion bands may be assigned. This range of motion contains only movable elements and is the rotor and its bars. The meshing density was controlled from the user by using the optimized meshing setting. And in order to obtain the accuracy of the analysis with more simulation time, the network density should be increased. This requires generating multiple nodes to estimate body area [6], figure (3) shows the under-test motor meshing.

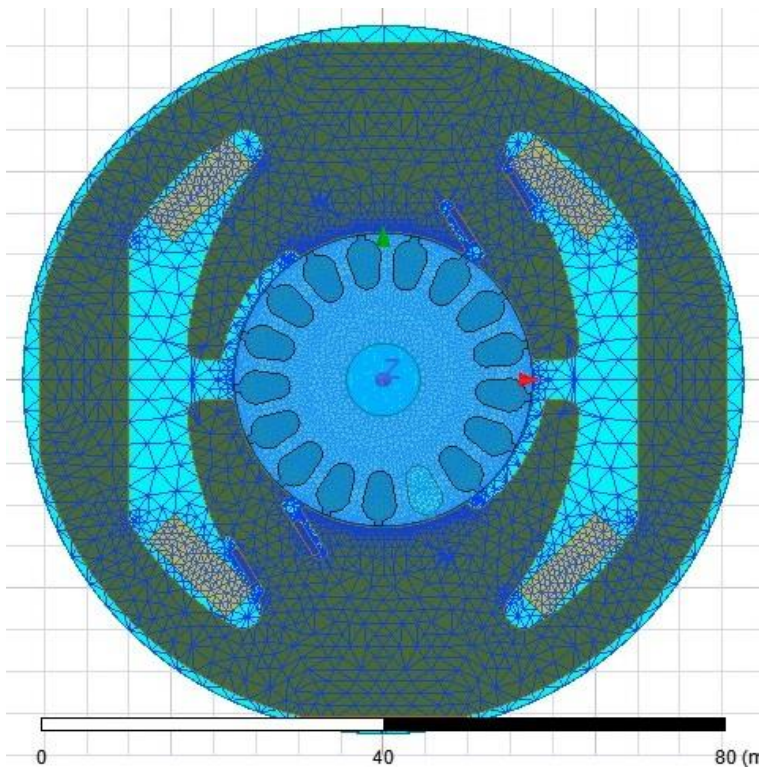

Figure 3-a. The mesh of SPIM

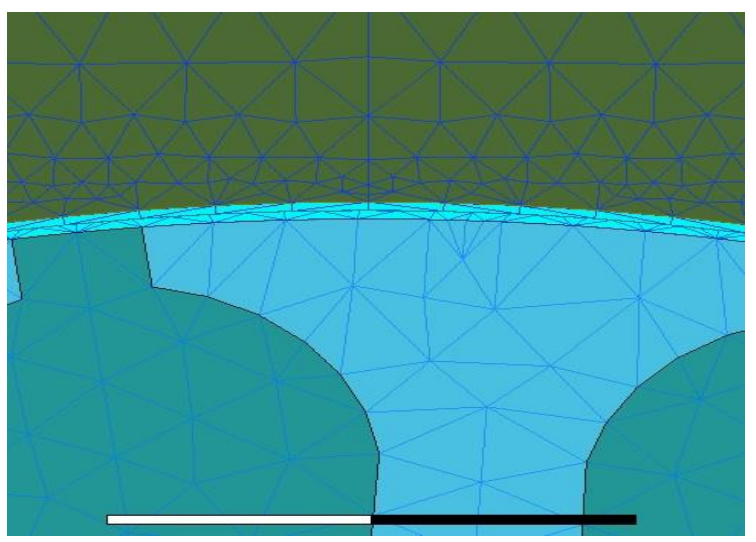

Figure 3-b. Zoom in airgap region 
For Maxwell 2D transient designs with cylindrical rotational motion setup, the transient solver can take into account the effects of skewed rotor slots by using a multi-slice model. To check the validity of model to analysis we test it at no load. Figure (4) shows the distribution of magnetic flux lines in the different parts of the motor model, and figure (5) shows the magnetic flux density distribution in it. From these two figures we observed a logical distribution of magnetic flux, and the levels of magnetic saturation in motor core which give a good indication to the motor designer to discover the validity of motor design and make any modifications and improvements in it. The saturation factor is important for such motors, and it varies greatly when the slip varies from zero to one [7].

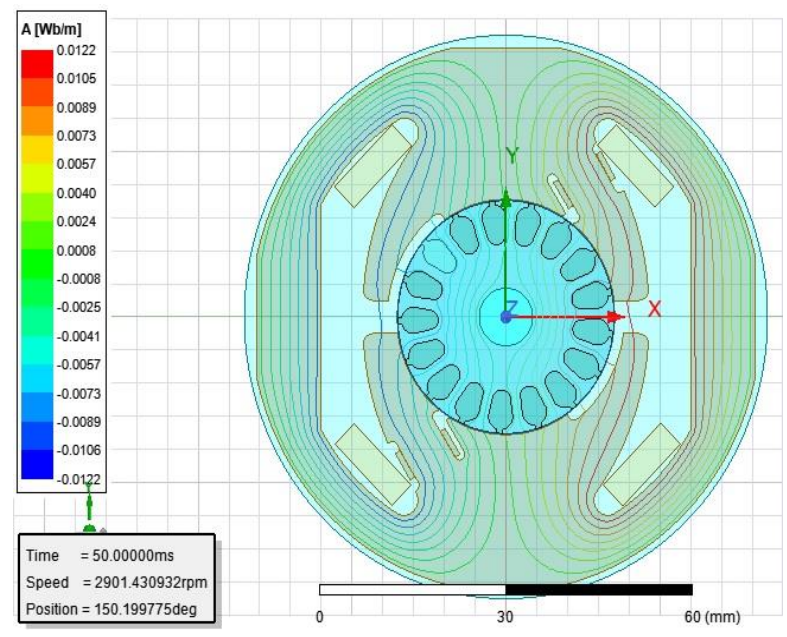

Figure 4. Magnetic flux lines

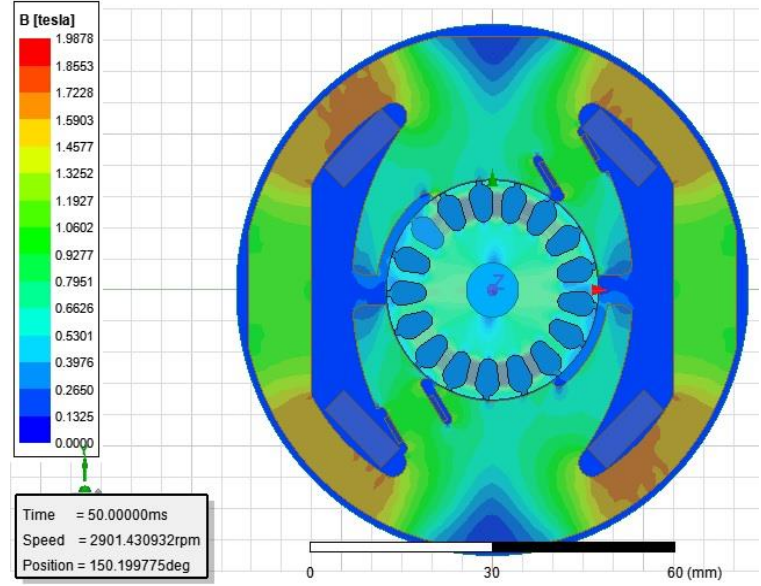

Figure 5. Magnetic flux density

\section{Results and Discussion}

After transient analysis of test shaded pole motor using Maxwell2D software, we calculated motor main winding current, shaded ring current, and torque, as showed in figures $(6,7,8)$ respectively.

Table (2) shows the Comparison between Maxwell2D FEM results and analytical results adopted in the same motor test in [8].

Table 2. Comparison between Maxwell FEM and Analytical Results

\begin{tabular}{lllll}
\hline & Unit & FEM & Analytical & Error \\
\hline Main current & $\mathrm{A}$ & 0.64 & 0.70 & $8.6 \%$ \\
Shaded current & $\mathrm{A}$ & 128 & 135 & $5.2 \%$ \\
Starting torque & $\mathrm{mN} . \mathrm{m}$ & 18 & 20 & $10 \%$ \\
Rated torque & $\mathrm{mN} . \mathrm{m}$ & 68 & 75 & $9.3 \%$ \\
Max. torque & $\mathrm{mN} . \mathrm{m}$ & 84 & 78 & $7.6 \%$ \\
\hline
\end{tabular}




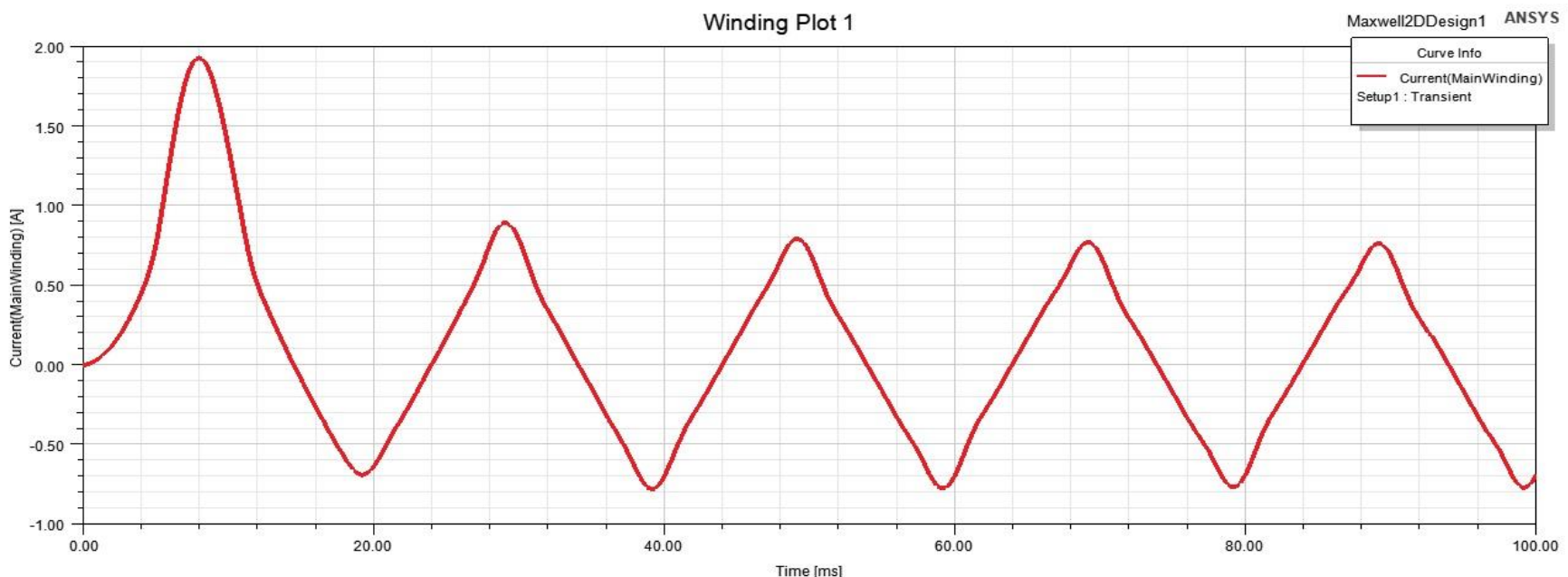

Figure 6. Main Winding Current

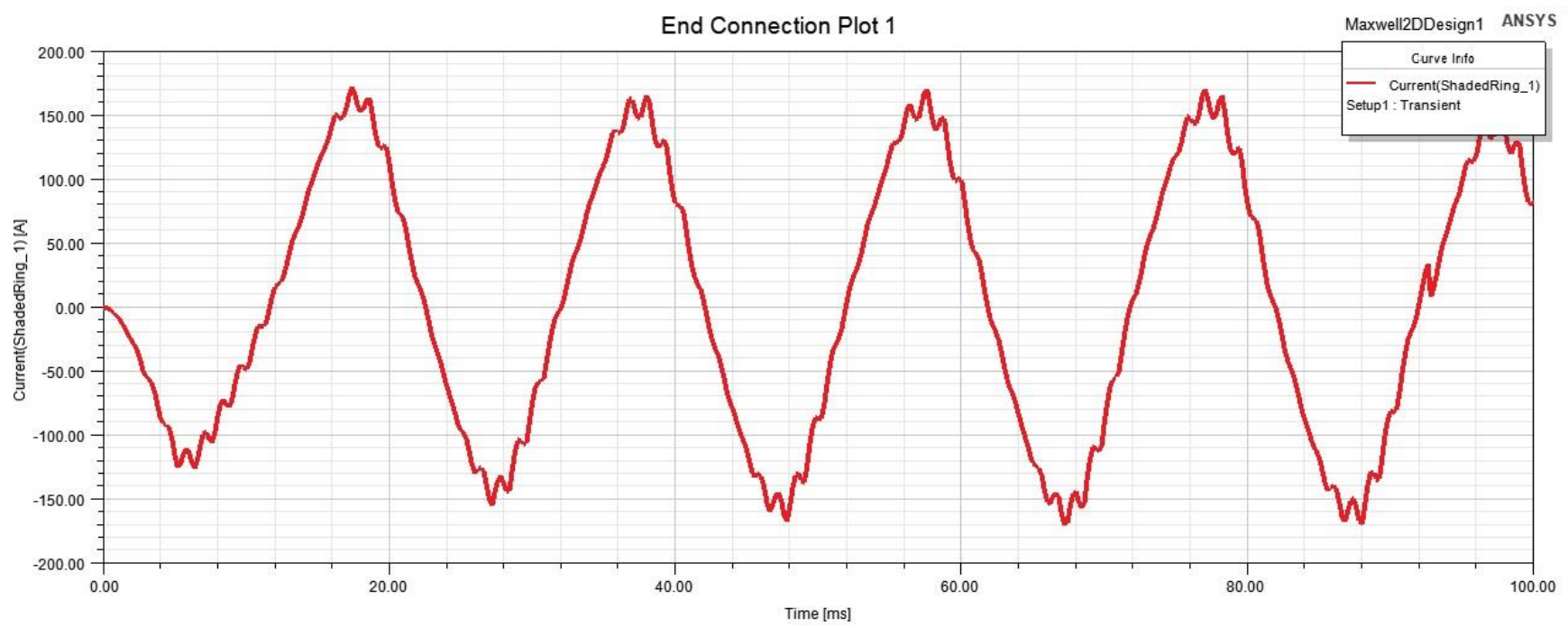

Figure 7. Shaded ring current

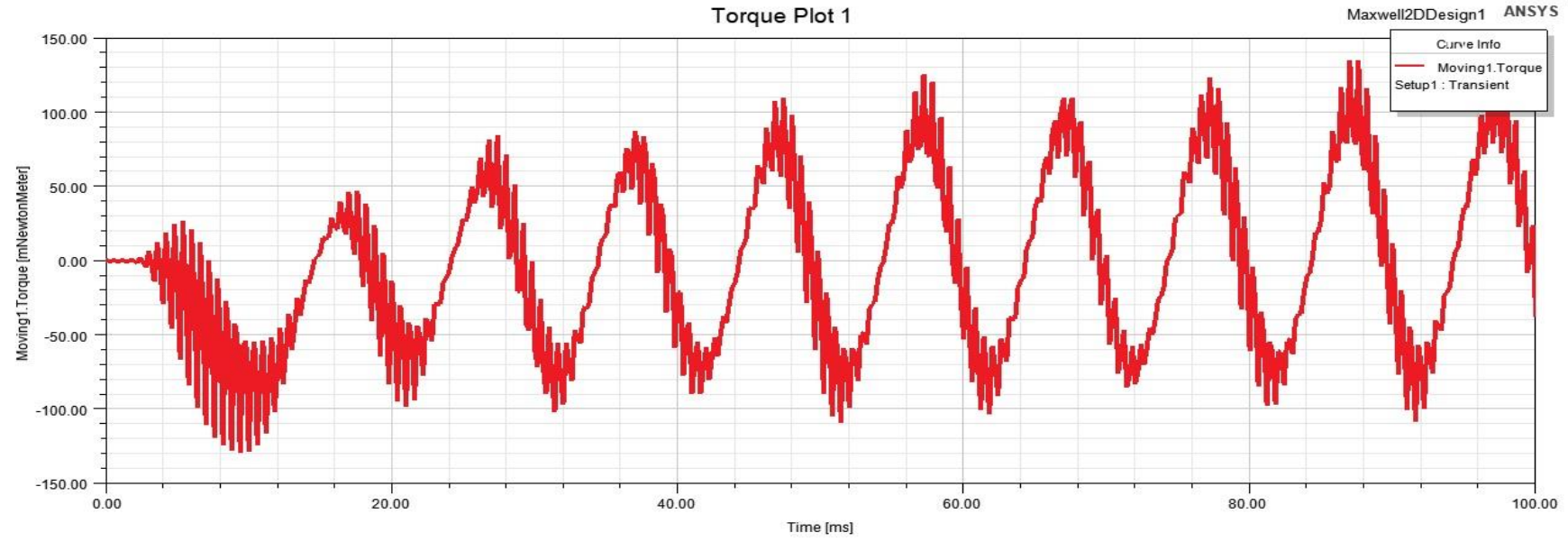

Figure 8. The Torque 


\section{Conclusion}

A proposed straightforward method combined with the facilities of both Mxwell2D and AutoCAD software has been presented for modeling a reluctance augmented shaded pole induction motor. After, that a two-dimensional finite element analysis has been adopted successfully on this proposed motor model to estimate it torques and currents by Maxwell2D. The FEM and analytical results show a good agreement, so the proposed method can be adopted in modeling and analysis of all types of shaded pole motors and assist its designers and researchers to overcome their difficulty in modeling and analyzing.

\section{Acknowledgment}

The authors wish to thank the Department of Electrical Engineering, Mustansiriyah University of Iraq for providing the facilities to continue this research work.

\section{Conflict of Interest}

The authors confirm that the publication of this article causes no conflict of interest.

\section{References}

1. Chang, S. S. L. (1951). "Equivalent circuits and their application in designing shaded pole motors". Transactions of the American Institute of Electrical Engineers, 70(1), 690-699.

2. Petkovska, L., Cundev, M., \& Sarac, V. (2002). "FEM analysis of asymmetrical magnetic field in electrical machines".

3. Sarac, V., \& Cundev, D. (2012). "Electromagnetic fields calculation at single phase shaded pole motor". Electrotechnica\&Electronica, 47(7 $-8 / 20), 41-45$.

4. Dalcali, A., \& Akbaba, M. (2016). "Comparison of $2 D$ and $3 D$ magnetic field analysis of single-phase shaded pole induction motors". Engineering Science and Technology, an International Journal, 19(1), 1-7.

5. Shamlou, S., \& Mirsalim, M. (2015, November). "A new restructured shaded pole induction motor-3D finite element analysis and experimental verification". In 2015 30th International Power System Conference (PSC) (pp. 136-141). IEEE.

6. Błaszczyk, P. (2009). "Optimization of shaded-pole micromotor using evolutionary algorithms".

7. Perret, R., \& Poloujadoff, M. (1976). "Characteristics analysis of saturated shaded pole induction motors". IEEE Transactions on Power Apparatus and Systems, 95(4), 1347-1353.

8. Al Samer, F. A. J. (2000). "Shade Pole Motors Optimization". University of Technology, Department of Technological Education. 